\title{
In Vivo Imaging
}

National Cancer Institute

\section{Source}

National Cancer Institute. In Vivo Imaging. NCI Thesaurus. Code C48799.

A microscopic visual representation of a biological component inside the body. The imaging procedure often utilizes a variety of diagnostic tools to provide insight regarding disease states, molecular characterization, and biological processes. 